\title{
THE FINANCIAL IMPACT OF MEDICAL MALPRACTICE CLAIMS AFTER THE AFFORDABLE CARE ACT ON THE PROPERTY \& CASUALTY INSURANCE INDUSTRY
}

\author{
Kelli Pedersen
}




\section{ABSTRACT}

In 2010, the Affordable Care Act was signed into law with various provisions taking effect over the following years, specifically the individual mandate in 2014. This reform drastically impacted the entire insurance industry, not simply health insurance. Many prior studies, however, focused only on how ACA impacted health insurance. Early estimates indicated that health insurers might transfer costs to property and casualty insurers, which would significantly impact the profitability of these companies. Despite the association of medical malpractice with healthcare, property and casualty insurers actually write the policies for medical malpractice incidents. Therefore, I chose to exclusively examine how the Affordable Care Act impacts the practices of property and casualty insurers that write medical malpractice policies. My study worked to answer three questions: (i) the change in the number of medical malpractice reports, especially in Medicaid expansion states, (ii) the change in the dollar amount of these claims, and (iii) the impact to the industry's net income. Using statistical tests and regressions based on sample data of the number of medical malpractice reports and the inflation-adjusted dollar amounts of these claims in each of the 50 states from 2003 to 2018, healthcare consumption expenditures, and the number of individuals with health insurance, I concluded that the number of malpractice reports has increased and the dollar amount of claims has decreased since the enactment of the Affordable Care Act. However, only a portion of these changes can be attributed to the Affordable Care Act, as the additional number of people insured played a small role in the variations of the medical malpractice environment; rather, healthcare consumption expenditures substantially altered the medical malpractice statistics. Ultimately, I concluded that the changes that occurred in the medical malpractice claims after the passage and enactment of the Affordable Care Act had very little impact on the profitability of the property and casualty insurance industry. 


\section{INTRODUCTION}

The Patient Protection and Affordable Care Act ("ACA", "Affordable Care Act", or "the Act") was passed in 2010 with the intent of providing nearly universal health insurance coverage in the United States that would enable all individuals to have access to healthcare (Kaiser Family Foundation, 2013). Although considerable studies have been conducted on the legislation's impact on the financial performance of health insurance companies before, at, and after the passage, there is little information regarding the effect of the law on non-health insurance providers. The insurance industry is extremely dynamic, operating across multiple lines including health, property \& casualty, life, and reinsurance. Looking at the insurance industry as a whole, I could see how different lines of insurance move together, as regulation does not have a singular impact on only one line of insurance, which prompted my interest in exploring a wider range of impacts of the Affordable Care Act (Kadiyala \& Heaton, 2017).

Specifically, this thesis will address the financial impact of the Affordable Care Act on non-health insurance providers, especially liability insurance, which includes medical malpractice. The Affordable Care Act introduced a number of provisions that increased the risk exposure of health insurers through the expansion of insurance coverage to low-income and high-risk individuals (Kaiser Family Foundation, 2018) (Barnett \& Berchick, 2018). This action changed the landscape of the insurance industry, creating a domino effect between different lines (Casualty Actuarial Society, 2013). As health insurance claims become more costly, other forms of insurance are impacted by this trend (Insurance Research Council, 2014). Therefore, early estimates by researchers before the enactment of the legislation indicated that instances of medical malpractice were likely to increase, as more individuals receive access to healthcare (Auerbach, Heaton \& Brantley, 2014) (Antin, Ehrlich \& Epstein, LLP, 2014). This thesis will test these assumptions and analyze the true magnitude of the impact of ACA by looking at the number of medical malpractice incidents, the dollar amounts of these claims, the expansion of the Medicaid program in certain states, and the profitability of the property and casualty insurance industry before, at, and after the enactment of the legislation. Ultimately, I want to determine whether changes in the financial performance of property and casualty insurance companies since the passage of the Affordable Care Act can be attributed to the changes in the regulatory environment through the enactment of this reform and its various provisions. 


\section{RESEARCH QUESTIONS}

This thesis attempts to answer multiple research questions, which include:

i. Did the Affordable Care Act increase the number of instances of medical malpractice reports, as a higher number of individuals carry health insurance and have greater access to health services? Is this change greater in Medicaid expansion states?

ii. Did the passage of the Affordable Care Act decrease the dollar amount of these claims, as the increased prevalence of health insurance weighs on the final claim amount?

iii. If questions one and two are significant, did these changes impact the profitability of the property and casualty insurance industry?

With the use of data and studies, the remainder of this thesis will attempt to answer the above questions. 


\title{
LITERATURE REVIEW
}

\author{
Affordable Health Care Act
}

The Affordable Care Act was signed into law on March 23, 2010 by President Barack Obama to provide healthcare reform. The law has been enacted through the implementation of a number of provisions since 2010, which will likely continue to roll out through 2020 (Kaiser Family Foundation, 2013). The intent of this legislation was to expand health insurance with the goal that it would become universally adopted by eliminating the financial barriers to acquiring insurance. Additionally, other purposes of the bill included the expansion of Medicaid and reduction of healthcare costs. In 2017, Congress voted to repeal the individual mandate of the Affordable Care Act. The individual mandate requires that citizens and legal residents of the United States have health insurance or face a tax penalty (Kaiser Family Foundation, 2013). Beginning in 2019, this provision will no longer be in place, which will likely result in an increase in the number of uninsured individuals.

Through the Affordable Care Act, the number of insured Americans grew substantially. In 2013, there were approximately 44 million uninsured individuals among the nonelderly in the United States (Kaiser Family Foundation, 2018). In 2016, this number was approximately 27 million through the efforts of the Affordable Care Act (Kaiser Family Foundation, 2018). Although the bill made large strides in making health insurance more accessible, many people still remain uninsured due to the cost of insurance, which is why the growth of the number of insured individuals has slowed since the passage of the ACA in 2010 (Barnett \& Berchick, 2017). Historically, the percentage of uninsured nonelderly Americans was approximately 16 percent (Kaiser Family Foundation, 2018). In 2016, that rate was only 10 percent (Kaiser Family Foundation, 2018).

Charles Courtemanche, James Marton, Benjamin Ukert, Aaron Yelowitz, and Daniela Zapata (2017) examine the impact of the Affordable Care Act on both Medicaid expansion and non-Medicaid expansion states to analyze the overall impact of the legislation on the number of uninsured. States could opt in or out of Medicaid expansion through the Supreme Court case National Federation of the Independent Business (NFIB) v. Sebelius, which ruled that states were not provided enough notice in order to force them to expand their Medicaid programs to low-income Americans with incomes less than 138 percent of the Federal Poverty Line (Musumeci, 2012). Currently, there are 14 states that did not opt into Medicaid expansion and 32 that did, leaving four additional 
states that are likely to implement the expansion in 2019. The authors refer to the Affordable Care Act's approach as a "three-legged stool," comprised of reforms to the non-group insurance market, the individual mandate, and the expansion of Medicaid and subsidies (Courtemanche, Marton, Ukert \& Yelowitz, 2017). These three legs work in conjunction with one another to reform the healthcare environment of the United States and provide insurance and care to all individuals in the United States. The first leg led to the creation of the "Federal Exchange", which is a health insurance marketplace that aids in the procurement of insurance policies for small businesses and individuals. The second leg, the individual mandate requires that individuals meet the minimum health insurance coverage. This topic is discussed in more detail above. The third leg, which expands Medicaid and subsidies, provides resources in the form of tax credits to individuals with incomes that lie between 100 and $\mathbf{4 0 0}$ percent of the Federal Poverty Line. Ultimately, it is estimated that the percentage of insured individuals, assuming Medicaid expansion, would increase by 5.9 percent, while that increase would only be 2.8 percent without Medicaid expansion (Courtemanche, Marton, Ukert \& Yelowitz, 2017). This study demonstrates the causal relationship between the level of Medicaid expansion and the rate of increase in the number of insured individuals in the United States.

Forms of Insurance

\section{PROPERTY AND CASUALTY INSURANCE}

Property and casualty insurance is a larger umbrella of insurance coverage that includes liability insurance, which is discussed in more detail below. This line also provides coverage on personal belongings, like a home or car. The main players in the space include companies such as State Farm Automobile Insurance Company, Berkshire Hathaway Inc., The Allstate Corporation, Liberty Mutual Insurance Group Inc., and The Travelers Companies Inc. These companies underwrite insurance for automobiles, homeowners, titles, workers' compensation, and medical malpractice.

\section{MEDICAL MALPRACTICE INSURANCE}

According to the American Board of Professional Liability Attorneys, medical malpractice can be defined as an act of negligence or omission on the part of a doctor, hospital, or other medical service provider that causes harm to the individual being treated. 
Therefore, medical professionals purchase medical professional liability insurance or medical malpractice insurance to financially protect themselves against any wrongdoing. This is likely one of the largest insurance segments that has been impacted by the Affordable Care Act (Chirba \& Noble, 2013), as more people have increased access to health services through the expansion of health insurance (Davis 2012), increasing the quantity and likelihood of malpractice and malpractice cases, as noted in the section above. The Affordable Care Act makes two specific references to medical malpractice, including Sections 6801 and 10607, which are described in more detail below (Redhead \& Heisler, 2013).

- SECTION 6801: SENSE OF THE SENATE REGARDING MEDICAL MALPRACTICE

This section encourages the healthcare industry, states, courts, and Congress to undertake an analysis and reform of medical malpractice and medical liability insurance, especially in regard to the current litigation system. Additionally, the section presents the idea that states should work to "improve access to liability insurance." If these stakeholders engage in reform, it is likely to shake up the current liability insurance landscape, including claims costs, premiums, and the number of medical providers with coverage.

- SECTION 10607: State DEMONSTRATION PROGRAMS to Evaluate Alternatives to CurRent Medical TORT LITIGATION

This section provides $\$ 50$ million of grants to states through the Department of Health and Human Services to produce and test substitutes for the current tort litigation system in medical malpractice trials in attempt to decrease the number of cases. 
In addition to these direct references, the Affordable Care Act is having an indirect impact on medical liability cases. Currently, it is being argued that damages should only include the insurance premiums and out-of-pocket spending for the medical service (Zigrang, 2017). With the Individual Mandate of the Affordable Care Act, it is assumed that a large majority of individuals are covered by health insurance; therefore, a substantial portion of their medical expenses have been covered already, so the damages should no longer equate to the total price of the medical service, as the individual would be receiving a larger payment than he or she made. This would likely decrease the costs of liability claims from medical malpractice cases.

\section{Estimates of The Affordable Care Act's Impact on Liability Insurance}

Liability insurance protects against personal injury and property damage. This includes coverage of legal costs and settlements if a liability case is brought to court. Some of the main forms of liability insurance include workers' compensation, product liability, commercial liability, professional indemnity, and commercial general liability insurance.

Early studies conducted in 2014 provide estimates of the potential influence of the Affordable Care Act on the liability insurance industry; however, these studies were performed before the full impact of the legislation could take effect, as the individual mandate did not take effect until 2014. Therefore, early studies are not conclusive due to a lack of data and only serve as projections for future values. David Auerbach, Paul Heaton, and lan Brantley from Rand Health Quarterly (2014) analyzed the potential impact of the Affordable Care Act on liability insurance, such as medical malpractice, auto, and workers' compensation. Specifically, the influence of the legislation on the cost of claims. A large portion of the cost of medical claims for health insurance providers is subsidized via liability insurers through legal settlements. For example, medical malpractice cases often result in the payment of medical expenses if the party is found guilty, lowering the cost of the health insurance claim. Therefore, the ACA can impact the cost of liability insurance, as health insurance coverage becomes more widespread and thus medical malpractice payments will fluctuate. There are individual legal and behavioral mechanisms, including the individual substitution effect, collateral source effect, provider treatment effect, and direct fee effect, which are discussed in more detail below, that impact the 
costs of liability claims.

- INDIVIDUAL SUBSTITUtION EFFECT: Liability insurance is used to cover conditions that have been untreated but are not a result of the accident that occurred or conditions that have become worse because the subject does not have health insurance to treat the issue in a timely manner.

- Collateral Source EfFect: Evidence cannot be submitted to the court that demonstrates that health insurance companies have paid for the accident in question already, as this could skew the results.

- PROVIDER TREATMENT EFFECT: The idea that healthcare providers give more attention and care to patients with health insurance because they know they will likely receive payment.

- DIRECT FEE EFFECT: Many liability insurers base their payments on Medicare rates, but the Affordable Care Act alters some of the rates that providers receive from Medicare.

- Medical Malpractice Volume EfFect: Since people with health insurance probably frequent the doctor and other medical providers more often, they would be more likely to experience medical malpractice and file a liability claim.

Ultimately, Auerbach, Heaton, and Brantley (2014) estimated the impact of the ACA on these different mechanisms and how that affects the cost of liability claims. The conclusions for the different lines of liability insurance are discussed below.

- INDIVIDUAL SUBSTITUTION EFFECT: With the passage of the ACA, this mechanism now yields a cost decrease in auto and workers' compensation claims, as it is more likely that a larger number of people will be able to seek medical treatment for existing problems through health insurance. 
- Collateral Source EFFect: The collateral source effect decreases the cost of auto and medical malpractice liability claims, as health insurance becomes more widespread because the courts now factor this information into their rulings.

- PROVIDER TREATMENT EFFECT: Through the ACA, this mechanism only decreases the liability claims costs of auto liabilities, as doctors now do not need to question whether a patient has health insurance. Questions of payment have become less of a concern; therefore, the provider treatment effect is not as prevalent.

- DIRECT FEE EFFECT: The direct fee effect provides cost savings to auto and workers' compensation claims, as the ACA has adjusted the rates with which liability insurers base their payments off of, which ultimately led to a reduction in the cost of claims.

- Medical malpractice Volume EfFect: This is the only mechanism that has led to a cost increase in medical malpractice. Now, more people have access to healthcare providers through the Affordable Care Act, so the number of malpractice cases have likely also increased.

Overall, the cumulative impact of the ACA's effect on these different mechanisms yields a substantial change in the cost of liability claims. Therefore, the Affordable Care Act has a far-reaching effect on the insurance industry outside of simply health insurance. As seen above, the impact to liability insurance companies can be substantial, as the Affordable Care Act has likely influenced the frequency and cost of claims in medical malpractice liability insurance, since more individuals have access to healthcare through this legislation. A further study, using current data could provide greater clarity on the varying arguments in these studies.

Medicaid Expansion and Medical Malpractice Relationship

As mentioned above, a key portion of the Affordable Care Act includes the 
expansion of Medicaid to low-income individuals who generate incomes that are less than 138 percent of the Federal Poverty Line. However, the Supreme Court case National Federation of the Independent Business (NFIB) V. Sebelius determined that states could choose whether to opt in or out of the Medicaid expansion program. This has created substantial discrepancies in the number of individuals receiving health insurance coverage through the public market. In a study conducted by Vasu Sunkara and Sara Rosenbaum (2016), the researchers determined that despite the overall proportion of uninsured individuals in the United States dropping from approximately 16.3 percent to 12.7 percent; individuals in non-expansion states were twice as likely to remain uninsured at 17.5 percent versus 9.8 percent in expansion states. Therefore, states that did accept the Medicaid expansion program are more likely to see decreases in the number of low-income individuals without health insurance.

Furthermore, Medicaid expansion states have seen increases in access to and the utilization of healthcare services; therefore, in these states, healthcare expenditures increased as well. Samuel Opoku, Emmanuel Akowuah, and Bettye Apenteng conducted a study to determine the extent to which the expansion of Medicaid impacted the severity of medical malpractice claims, as more individuals entered the healthcare system through the legislation. Ultimately, the researchers concluded that the presence of an expanded Medicaid program decreased the payment of medical malpractice claims. Although a larger portion of people are seeking care in Medicaid expansion states, this does not cause higher malpractice payments, despite the initial belief that the flooding of new entrants to the healthcare system could lead to a greater expansion of technology and worsened care, which would likely cause increased medical malpractice claims, increasing cost pressures on the property and casualty insurance industry. However, the study concluded that these factors did not inflate the severity of medical malpractice claims.

\section{DATA COLLECTION}

In order to determine the Affordable Care Act's financial impact on liability insurance providers, specifically within medical malpractice, I need to determine (i) if the quantity of medical malpractice claims increased after the passage and implementation of the legislation, especially in Medicaid expansion states where the Act is most prominent (ii) whether there was an increase in the dollar amount of these liability claims, and (iii) if the changes in the profitability of property and casualty insurance industry can be attributed to 
the Affordable Care Act.

Therefore, I collected data from the Census Bureau, Centers for Medicare and Medicaid Services, the National Practitioner Data Bank, the Insurance Information Institute, and the National Association of Insurance Commissioners and the Center for Insurance Policy and Research. All of the data that was collected for this study is publicly available information. Although the data comes from a multitude of sources, I collected all of the data for each data category from the same source. For example, all data on the quantity and amount for medical malpractice claims comes from the National Practitioner Data Bank to ensure consistency across all of my data points throughout the entire timeframe. The data points spanned 2003 to either 2017 or 2018 , depending on the release of the data, as some information for 2018 is not currently available. This timeframe factors in 15 years of information; therefore, the analysis is not concentrated around a single event that would skew the results. Since the Affordable Care Act was passed in 2010, I wanted to consider multiple years before and after its passage to gain a more holistic view of the industry. The legislation was enacted in waves with the most substantial provision, the individual mandate, taking place in 2014. The majority of provisions were enacted by 2016, so for the purposes of this study 2016 is considered the final year of implementation.

To collect the quantity of medical malpractice reports and the total dollar amounts of these claims, I used information from the National Practitioner Data Bank, as certain healthcare professionals are required to report specific medical malpractice instances and payments to the U.S. Department of Health and Human Services. Using this database, I pulled data from 2003 to 2018 for all 50 states, including the number of incidents and the inflation-adjusted dollar amount of malpractice payments in each state over the specified timeframe. This yielded 800 data points for each metric, which serves as sample data for the total malpractice reports. Additionally, I reproduced the data for the number of medical malpractice reports for only Medicaid expansion states to isolate the influence of the legislation on these states alone, which yielded 592 data points.

Additionally, I collected the number of individuals in the United States with health insurance from 2003 to 2017 from the Census Bureau. This statistic provides a benchmark for the effectiveness of the Affordable Care Act. Using this data point, I calculated the year-over-year differences and annual growth rates to measure the extent that the legislation expanded the availability of health insurance. This data was used as an $\mathrm{x}$-variable in many of the regressions 
that I ran in order to test whether the Affordable Care Act was the true catalyst for change in malpractice instances and dollar amounts.

The Centers for Medicare and Medicaid Services provided data on the amount of health care expenditures in the United States from 2003 to 2017. This is a significant data point for the study, as it provides a benchmark on whether the increased access to healthcare services, technology, and testing through widespread insurance increases or decreases the number of incidents and the dollar amount of medical malpractice claims. It introduces another factor into the study, rather than simply relying on solely the number of individuals with health insurance. Prior research, which relied on preliminary data before the Affordable Care Act fully went into effect, varied on whether increased spending on healthcare would play a role in the dollar amount of medical malpractice claims, so the incorporation of this metric with updated data is meant to provide clarity on the issue.

The final data point that I collected, the net income of the property and casualty insurance industry, came from the Insurance Information Institute. Like the other metrics that I analyze, this statistic was collected from 2003 to 2017 for consistency and sufficiency purposes. The Insurance Information Institute has only released data up until 2017 and has not made 2018 data available yet. In order to generate these numbers, the Institute collects figures from all of the property and casualty insurance companies, such as State Farm Automobile Insurance, Berkshire Hathaway, Liberty Mutual, Allstate Corporation, and Progressive Corporation. Then, the Insurance Information Institute compiles this information to produce one industry statistic. This data point is essential to understand the higher-level implications of the Affordable Care Act on the property and casualty insurance industry. Ultimately, I want to determine if this regulation had an impact on the bottom line of companies in the industry.

The data points described above, including the instances and dollar amounts of medical malpractice reports in each state, the number of individuals with health insurance, the healthcare consumption expenditures, and the net income of the property and casualty insurance industry, are used to create the t-tests and regressions that are discussed in the next section.

\section{HYPOTHESIS}

For the purposes of this thesis, I constructed two hypotheses to answer the 
first two research questions, described below. Since I collected sample data from each state, these tests are used to infer the changes in the population data, which would be medical malpractice incidents and claims in the United States.

i. Did the Affordable Care Act increase the number of instances of medical malpractice reports, as a higher number of individuals carry health insurance and have greater access to health services? Is this change greater in Medicaid expansion states?

NULL HYPOTHESIS (HO): The mean of the annual percentage increase in the number medical malpractice reports for all 50 states over the specified time periods is less than or equal to zero.

ALTERNATIVE HYPOTHESIS (H7): The mean of the annual percentage increase in the number medical malpractice reports for all 50 states over the specified time periods is greater than zero.

In order to test this first hypothesis, I constructed one-tailed t-tests for a variety of timeframes, including 2013 to 2017, 2009 to 2017, 2013 to 2015, and 2013 to 2016. I choose to use a multitude of timeframes to isolate different impacts of the Affordable Care Act. The descriptions of these timeframes are listed below.

- 2013 - 2017: The individual mandate of the Affordable Care Act was implemented in 2014, which was the most notable provision of the legislation, and the majority of provisions were enacted by 2016 , so this can be considered "full enactment" for this study. Therefore, this time period looks at one year before the first major provision and one year after the majority of the provisions had been enacted.

- 2009 - 2017: This is the longest time period that spans the enactment of multiple provisions of the Affordable Care Act. Since the bill was passed in $\mathbf{2 0 1 0}$ with the first provisions taking effect during that year, I accounted for one year before its passage and one year after "full enactment" of the Act. 
- 2013 - 2015: This is the shortest time period, which isolates the impact of the individual mandate alone, which came into effect in 2014. Therefore, the purpose of this timeframe is to show the change from one year before to one year after the healthcare exchange went live, prompting the largest spike in the number of individuals with health insurance.

- 2013 - 2016: This timeframe represents one year prior to the enactment of the individual mandate to the year in which the bill can be considered nearly fully implemented. Since few provisions remain and the increased presence of political uncertainty, the majority of the impacts of the Affordable Care Act have been captured in the data by 2016.

Using the above timeframes, I ran four one-tailed t-tests at a 95 percent confidence level, using annual percent changes in each state for the specified dates. To calculate these annual percent changes, I used the RATE function in Excel and set the number of periods to the number of years between the dates, the present value as the number of malpractice incidents during the first year of the time period, and the future value as the number of malpractice incidents during the last year of the time period. Using the returns from the individual states, I calculated the mean and standard deviation of the samples, which were used in the calculation of the t-statistic. I then excluded the data points from non-expansion states and ran the calculations with the new data set, producing the returns, average, standard deviation, and t-statistics for each time period for Medicaid expansion states and non-expansion states individually. In order to test the impact of the affordable care act in Medicaid expansion states versus non-expansion states, I chose to run a one-tailed twosample t-test with the following hypotheses.

NULL HYPOTHESIS (HO): The mean of the annual percentage increase in the number of medical malpractice reports in Medicaid expansion states is less than or equal to the annual percentage increase in the number of medical malpractice reports in non-Medicaid expansion states over the specified time periods. 
ALTERNATIVE HYPOTHESIS (H7): The mean of the annual percentage increase in the number of medical malpractice reports in Medicaid expansion states is greater than the annual percentage increase in the number of medical malpractice

ii. Did the passage of the Affordable Care Act decrease the dollar amount of these claims, as the increased prevalence of health insurance weighs on the final claim amount?

NULL HYPOTHESIS (HO): The mean of the annual percentage increase in the number medical malpractice reports for all 50 states over the specified time periods is less than or equal to zero.

ALTERNATIVE HYPOTHESIS (H7): The mean of the annual percentage increase in the number medical malpractice reports for all 50 states over the specified time periods is less than zero.

For my second research question, I used the same methodology as the tests conducted for research question one; however, I used the dollar amount data from each state over the specified time periods listed above. In order to construct the t-tests, I calculated the annual percentage change over each time period for medical malpractice claims and the mean, standard deviation, and t-statistics of the returns.

To supplement these hypothesis tests, I ran multiple regressions to substantiate my claims and isolate the true catalysts of these changes and whether the factor of time or the Affordable Care Act is attributable. Therefore, the three regressions that I ran over the time period 2003 to 2017, using the data that is discussed in the prior section, include (i) medical malpractice incidents on individuals with health insurance and healthcare consumption expenditures, (ii) medical malpractice payments on individuals with health insurance and healthcare consumption expenditures, and (iii) medical malpractice payments on individuals with health insurance, healthcare consumption expenditures, and medical malpractice incidents. Through these regressions, I identify the variables that are significant, according to t-tests, which is how I determine what variables have a substantial impact on medical malpractice incidents and claims. I chose to use the number of people with health insurance and healthcare consumption expenditures because they serve as proxies for the impact of the Affordable Care Act. Increasing the number 
of people with health insurance the amount of healthcare consumption expenditures were the core purposes of the legislation; therefore, I assumed that these variables would capture the effect of the implementation of the Affordable Care Act.

For my final research question, which is listed below, I chose to run two regressions, including (i) the net income of the property and casualty insurance industry on medical malpractice incidents and (ii) the net income of the property and casualty insurance industry on the dollar amounts of medical malpractice claims, using data for the entire United States, rather than individual state data.

iii. If questions one and two are significant, did these changes impact the profitability of the property and casualty insurance industry?

The purpose of these regressions was to measure the high-level impact that medical malpractice incidents and claims have on the bottom line of the industry and whether the effects of these variables can be considered statistically significant.

\section{RESULTS}

For the first research question that I posed, which concerns the number of medical malpractice incidents after the Affordable Care Act, all of the tests that I ran over the four timeframes yielded statistically significant increases. During 2003 to 2017, the sample produced a mean for the annual percentage change in the number of malpractice incidents of 0.35 percent, a standard deviation of 4.70 percent, and a t-statistic of 3.74. From 2009 to 2017, the sample yielded a mean for the annual percentage change in the number of malpractice incidents of 1.46 percent, a standard deviation of 3.45 percent, and a t-statistic of 21.18. During 2013 to 2015, the sample returned a mean for the annual percentage change in the number of malpractice incidents of 2.00 percent, a standard deviation of 7.41 percent, and a t-statistic of 13.47 . Finally, the timeframe, 2013 to 2016, the sample generated a mean for the annual percentage change in the number of malpractice incidents of 0.81 percent, a standard deviation of 6.48 percent, and a t-statistic of 6.22. At a 95 percent confidence level, the one-tailed critical value is 1.677; any t-statistic that is greater than this value indicates a statistically significant increase. All of the t-statistics from the four timeframes, 3.74, 21.18, 13.47, and 6.22, are greater than the critical value, 1.677; therefore, the null hypothesis can be rejected. 
Therefore, I reached the conclusion that the true population mean of the annual percentage increase in the number medical malpractice reports for all 50 states over the specified time periods is greater than zero.

To test the second portion of my first research question, I ran a one-tailed two-sample t-test, using data on the annual percentage change in the number of medical malpractice incidents from both Medicaid expansion and nonexpansion states over the four periods specified above, including 2013 to 2017, 2009 to 2017, 2013 to 2015, and 2013 to 2016. However, none of these tests resulted in statistically significant t-values. From 2013 to 2017, the two-sample t-test generated a t-statistic 00.216 and p-value of .415 , which is not statistically significant at a 95 percent confidence level with an alpha of 0.05. During the timeframe of 2009 to 2017, the test resulted in a t-statistic of -0.072 and a $\mathrm{p}$-value of 0.471 , which is significantly greater than the alpha of 0.05 and not statistically significant. From 2013 to 2015, the two-sample t-test yielded a t-statistic of -0.284 and a p-value of 0.388 , which is not below the threshold of 0.05. For the final time period, 2013 to 2016, the test resulted in a t-statistic of 0.334 and a p-value of 0.370 , which again is greater than 0.05 . As mentioned above, the results of all of these tests are not significant; therefore, I failed to reject the null hypothesis that the mean of the annual percentage increase in the number of medical malpractice reports in Medicaid expansion states is less than or equal to the annual percentage increase in the number of medical malpractice reports in non-Medicaid expansion states over the specified time periods. Therefore, I concluded that the annual percentage increase in the number of medical malpractice reports in Medicaid expansion states is not greater than that of non-expansion states, so the presence of a Medicaid expansion program does not impact malpractice reports over any of the specified time intervals.

The tests for my second research question, concerning the changes in the dollar amounts of medical malpractice claims over certain time intervals that represent different impacts of the Affordable Care Act, resulted in varying outcomes. From 2013 to 2017, using the sample data from each state, I calculated a mean for the annual percentage change in the dollar amount of medical malpractice incidents of -0.04 percent, a standard deviation of 7.92 percent, and a t-statistic of -0.24, which does not pass the threshold of -1.677, which is the critical value for a one-tailed 95 percent confidence level t-test. During the time period of 2009 to 2017 , the calculations resulted in a sample mean for the annual percentage change in the dollar amount of medical malpractice incidents of -1.91 percent, a standard deviation of 4.80 percent, 
and a t-statistic of -19.92, which is significant because it is less than -1.677. For the timeframe of 2013 to 2015 , I calculated a mean for the annual percentage change in the dollar amount of medical malpractice incidents of 6.76 percent, a standard deviation of 22.37 percent, and a t-statistic of 15.10, which is substantially greater than -1.677. For the final time period, the data yielded a mean for the annual percentage change in the dollar amount of medical malpractice incidents of -2.85 percent, a standard deviation of 15.00 percent, and a t-statistic of -9.51, which is less than the critical value of -1.677.

The results from the regressions that I ran supplement the findings from the $t$-tests that are described above and provide additional context to the statistical outcomes. A summary of the results from each of the regressions are listed below.

- Equation (ApPENDIX A): Malpractice Incidents = 100,026.92 - 0.370 (Individuals with Health Insurance) + 21.558 (Healthcare Consumption Expenditures)

Overall, the statistics from this model indicate a strong relationship among the variables with a value for $\mathrm{R}$ of 0.940 , which is an extremely high correlation, and R-squared of 0.883; however, high $\mathrm{R}$-squared values can occur when regressing time series. Looking at the coefficients, I concluded that both variables are statistically significant, as individuals with health insurance and healthcare consumption expenditures have t-statistics of -3.042 and 5.920 and $\mathrm{p}$-values of 0.010 and .00007 , respectively. These $\mathrm{p}$-values are less than the alpha of 0.05 , indicating significance.

- Equation (APPENDIX B): Malpractice Payments $=-4,339.73+$ 0.065 (Individuals with Health Insurance) - 3.223 (Healthcare Consumption Expenditures)

The above multi-variable regression resulted in a value for $\mathrm{R}$ of 0.971 and R-squared of 0.944, which demonstrate a high correlation among the variables. In regard to the coefficients, I determined that both variables were statistically significant because individuals with health insurance and health consumption expenditures have t-statistics of 5.991 and -9.983 and p-values of 0.000063 and .00000036 , respectively. These extremely small $p$-values, which are 
- Equation (Appendix C): Malpractice Payments = -8,209.67

+ 0.079 (Individuals with Health Insurance) - 4.058 (Healthcare Consumption Expenditures) + 0.039 (Malpractice Incidents)

Analyzing the above model, I found that the multi-variable regression has a value for $\mathrm{R}$ of 0.977 and an $\mathrm{R}$-squared of 0.954 . The value for $\mathrm{R}$ indicates a high correlation among the variables, malpractice payments, individuals with health insurance, and healthcare consumption expenditures. Evaluating the coefficients, I found that the variables, individuals with health insurance and healthcare consumption, expenditures are statistically significant with t-statistics of 5.851 and -6.753 and $p$-values of 0.00011 and 0.000031 , respectively, which are less than the critical value of 0.05 . However, the variable, malpractice incidents, did not prove to be statistically significant with a t-statistic of 1.608 and a p-value of 0.136, which is above 0.05 .

For the final research question, which looks at the impact of medical malpractice instances and claims on the profitability of the property and casualty insurance industry, I ran two single-variable regressions. The results of the two models are described in more depth below.

- EquATION (APPENDIX D): Property and Casualty Insurance Industry Net Income $=32.273+0.00017$ (Medical Malpractice Incidents)

The above model has extremely small $\mathrm{R}$ and $\mathrm{R}$-squared values of 0.054, and 0.003, respectively. Only approximately 0.3 percent of the variation in the net income of the property and casualty insurance industry can be explained by the number of medical malpractice incidents. Additionally, the variable, medical malpractice incidents, is not considered statistically significant, as it has a t-statistic of 0.189 and a p-value of 0.853 , which is substantially higher than 0.05 , so the variable fails to be significant in this model. 
- EQUATION (APPENDIX E): Property and Casualty Insurance Industry Net Income $=32.273+0.00017$ (Medical Malpractice Payments)

Like the prior model, this regression has very small $\mathrm{R}$ and $\mathrm{R}$-squared values of 0.005 and 0.000026 , respectively, which indicates little to no relationship between the variables. Approximately, 0.017 percent of the variation in the net income of the property and casualty insurance industry can be explained by the dollar amount of medical malpractice payments. The independent variable, medical malpractice payments, is statistically insignificant, as it has a t-statistic of 0.018 and a $p$-value of 0.986 , which is not less than the alpha of 0.05. Therefore, medical malpractice payments have very little impact on the net income of the property and casualty insurance industry.

\section{DISCUSSION}

The results from the statistical tests discussed in the prior section lead to a variety of conclusions, concerning the financial impact of medical malpractice incidents and claims after the passage of the Affordable Care Act on the profitability of the property and casualty insurance industry.

In regard to my first research questions, I reached the following conclusions, concerning the frequency of medical malpractice claims after the passage and enactment of the Affordable Care Act. Each of the timeframes, including 2013 to 2017, 2009 to 2017, 2013 to 2015, and 2013 to 2016, indicated a statistically significant increase in the number of medical malpractice incidents after the passage and enactment of various provisions of the legislation. While initially I was inclined to attribute these increases solely to the Affordable Care Act, my regressions led me to question that conclusion. The first regression, medical malpractice incidents on individuals with health insurance and healthcare consumption expenditures, demonstrated the minimal impact that the number of people with health insurance has on the number of medical malpractice instances, as the coefficient for the independent variable is only -0.371, while the coefficient for healthcare consumption expenditures is 21.558 . Using these figures, I concluded that the addition of new entrants into the health insurance market did not substantially alter the number of reports of 
medical malpractice due to the negative coefficient and small value of the coefficient for the number of individuals with health insurance; however, with more advanced and sophisticated healthcare technology, procedures, and medical testing, individuals receiving care have increased touchpoints with the healthcare system (Conway, 2015). As individuals spend more on healthcare, the number of medical malpractice incidents rises substantially. For every one billion dollar increase in healthcare consumption expenditures, the number of medical malpractice incidents is expected to rise by 21.558 cases, on average. These numbers demonstrate the conclusion that the new entrants that flooded the insurance market are typically not the individuals that are reporting cases of medical malpractice; rather, individuals receiving more extensive care are likely filing these claims. While some of the changes in the number of medical malpractice incidents can be attributed to the Affordable Care Act because it increased the amount of healthcare consumption expenditures through expanding coverage for individuals who had health insurance prior to the legislation, like those with pre-existing conditions, the individuals who received new coverage after the passage did not substantially contribute to the increase in malpractice incidents.

Analyzing the one-tailed two-sample t-test for the second portion of my first research question, I concluded that the annual percentage change in medical malpractice incidents over every time period that I specified earlier, which represent the passage or enactment of the Affordable Care Act, is not greater in states with Medicaid expansion programs. This further substantiates my claim that the newly insured, which would likely be those who opt into Medicaid programs rather than purchase private insurance, are likely not the individuals filing medical malpractice reports. If the newly insured were reporting more cases of malpractice, then the data likely would have shown higher increases of malpractice incidents in Medicaid expansion states, as these states saw more drastic increases in the newly insured under the Affordable Care Act.

The statistical tests for the second research question, which looks at the percentage change in the dollar amount of medical malpractice claims after the Affordable Care Act, produced greater variety in their results. From the t-tests, I could conclude that there were decreases in the dollar amount of medical malpractice claims during the time periods of 2009 to 2017 and 2013 to 2016. On the other hand, I could not statistically conclude that there were decreases in the timeframes of 2013 to 2017 and 2013 to 2015. While these statistical tests produced mixed results, the most comprehensive timeline of the Affordable Care Act, 2009 to 2017, which encompasses a year before its 
passage to a year after the majority of provisions had been enacted, produced a significant decrease in the dollar amount of medical malpractice claims. The sample dataset of the dollar amounts of medical malpractice claims in each of the 50 states demonstrates that overall there was a decrease in the dollar amount of claims over the past few years; therefore, the Affordable Care Act has likely played some role in these changes, but the extent is unclear. Additionally, the regression results further clarity on the true catalysts of these changes. Similar to the conclusions drawn for the first research question, the regression of medical malpractice payments on individuals with health insurance and healthcare consumption expenditures demonstrates the assumption that the number of individuals with health insurance has little impact on the dollar amount of medical malpractice payments. The coefficient on the independent variable is only 0.065 , which is very close to zero, indicating that although the variable is statistically significant, the extent of its impact is small. As I mentioned earlier, it is likely that the newly insured under the Affordable Care Act are not the ones filing malpractice reports; therefore, they are also not the ones receiving payment (Rothstein, 2010). Their presence in the insurance market has little impact on the payout of malpractice cases, despite earlier theories that courts would now factor in the presence of health insurance for all individuals when determining claim amounts (Zigrang, 2017). It is likely that those who were previously filing malpractice claims already had some form of insurance (Opoku, Akowuah \& Apenteng). On the other hand, a large factor in the decreasing dollar amount of medical malpractice claims is the increase in healthcare consumption expenditures, which can be seen in the regression. For every additional one billion dollars spent on healthcare, the dollar amount of medical malpractice claims is expected to decrease by 3.224 million dollars. Therefore, I concluded that as people spend more on healthcare, they likely receive more tests and treatments and interact with more professionals and specialists, which increases the quality of care and decreases the likelihood of winning a malpractice claim (Greve, 2017). The increased healthcare expenditures can partially be attributed to the Affordable Care Act, as it allowed those with pre-existing conditions or minimal insurance to receive better care and more treatments; however, the legislation is not the only stimulus for the increase, as healthcare has become more expensive due to factors, like the rise of technology and specialized training and an aging population (Conway, 2015). Additionally, the second regression that I ran for this research question demonstrates the insignificance of the number of malpractice incidents on malpractice payments; this is likely due to the fact that incidents do not always 
lead to monetary claims.

For my final research question, which explores the relationships of medical malpractice incidents, the dollar amount of claims, and the profitability of the insurance industry, I concluded that the number of malpractice incidents and the dollar amount of the claims have very little impact on the profitability of the industry, as this portion of the business is likely very small for a majority of companies in the industry. These companies operate a variety of lines of insurance, such as auto, workers' compensation, and home insurance; therefore, a change in one line is not likely to drastically impact the industry's net income. Ultimately, I concluded that the passage and enactment of the Affordable Care Act did not substantially change the financial performance of the industry in regard to medical malpractice claims. However, there are limitations to this study, as there is only a limited amount of data having been released since the passage of the legislation. Therefore, with time the implications of the legislation will become clearer.

\section{CONCLUSION}

The Affordable Care Act was a significant piece of legislation that altered the environment that insurance companies operate in. This widespread reform introduced a health insurance exchange, the individual mandate, and the expansion of Medicaid programs. Although many studies have been conducted on the impact of this legislation on the health insurance industry, few have been conducted on how it affected the property and casualty insurance industry. Therefore, I set out to explore how this legislation impacted the profitability of property and casualty insurance companies in regard to medical malpractice through three research questions, including (i) the change in the number of medical malpractice reports, especially in Medicaid expansion states, (ii) the change in the dollar amount of these claims, and (iii) the impact to the industry's net income.

Ultimately, I concluded through the use of statistical tests and regressions that there have been increases in the number of reports and decreases in the dollar amount of medical malpractice claims over certain time periods. Although some of these changes can be attributed to the Affordable Care Act, as it has made healthcare more accessible to all, it is not the only stimulus for these changes. The number of individuals insured is a very small driver for the differences in the number of incidents and the dollar amount of claims, which I concluded through multiple multi-variable regressions. Increases in healthcare 
expenditures is the main catalyst for these changes, as individuals are receiving more care, treatment, and testing, which increase their interactions with the healthcare system but provides more comprehensive and safer care. This likely drives an increase in the number of reports but decrease in the dollar amounts of claims. The Affordable Care Act changed the landscape of healthcare and medical malpractice; however, the newly insured under this reform likely do not contribute substantially to these changes.

The purpose of this research was to explore how the Affordable Care Act impacted property and casualty insurers. Ultimately, I connected the information from the first two research questions, concerning the changes in malpractice claims, to the net income of the industry and found very little correlation between the two. Therefore, the Affordable Care Act did not alter the landscape of medical malpractice enough to impact the profitability of these companies. 


\section{REFERENCES}

Affordable Care Act and Medical Malpractice. (n.d.). Retrieved from https://www. gilmanbedigian.com/affordable-care-act

Antin, Ehrlich \& Epstein, LLP. (2014, September 05). Could the Affordable Care Act Mean An Increase In Medical Malpractice Suits? Retrieved from https:// www.aeelaw.com/could-the-affordable-care-act-mean-an-increase-inmedical-malpractice-suits/

Auerbach, D. I., Heaton, P., \& Brantley, I. RAND Corporation (2014). How Will the Patient Protection and Affordable Care Act Affect Liability Insurance Costs? Retrieved from https://www.rand.org/content/dam/rand/pubs/research_ reports/RR400/RR493/RAND_RR493.pdf.

Barnett, J. C., \& Berchick, E. R. US Census Bureau (2017, September). Health Insurance Coverage in the United States: 2016 (Publication No. P60-260). Retrieved from https://www.census.gov/content/dam/Census/library/ publications/2017/demo/p60-260.pdf

Casualty Actuaries Examining Impact of Healthcare Reform on Property/ Casualty Insurance Industry. (2013, March 27). Retrieved from https://www. casact.org/press/index.cfm?fa=viewArticle\&articlelD=2195

Chirba, M. A., \& Noble, A. A. (2013, May 14). Medical Malpractice, the Affordable Care Act and State Provider Shield Laws: More Myth than Necessity? Retrieved from http://blog.petrieflom.law.harvard.edu/2013/05/14/medicalmalpractice-the-affordable-care-act-and-state-provider-shield-laws-moremyth-than-necessity/

Conway, A. M. (2015, September). Insurers Face New Challenges with the U.S. Affordable Care Act. Retrieved from https://www.towerswatson.com/en-US/ Insights/Newsletters/Global/emphasis/2015/emphasis-2015-3-insurers-facenew-challenges-with-the-us-affordable-care-act 
Courtemanche, C., Marton, J., Ukert, B., Yelowitz, A., \& Zapata, D. (2017). Early Effects of the Affordable Care Act on Health Care Access, Risky Health Behaviors, and Self-Assessed Health. Institute of Labor Economics. Retrieved from http://ftp.iza.org/dp10649.pdf

Data Analysis Tool. (n.d.). Retrieved from https://www.npdb.hrsa.gov/analysistool/

Davis, A. C. (2012, April 30). The Impact of the Affordable Care Act on Medical Malpractice Litigation. https://doi.org/10.2139/ssrn.2048561

Greve, P. (2017, June 15). HealthTrek: Medical Malpractice Claim Trends in 2017. Retrieved from https://www.willistowerswatson.com/en-US/ insights/2017/06/insights-healthtrek-medical-malpractice-claim-trendsin-2017

Kadiyala, S., \& Heaton, P. RAND Corporation (2017, December 15). The Effect of Health Insurance Coverage Expansions on Auto Liability Claims and Costs. Retrieved from https://www.rand.org/pubs/working_papers/WR1214.html

Kaiser Family Foundation. (2013, April 25). Summary of the Affordable Care Act. Retrieved from https://www.kff.org/health-reform/fact-sheet/summary-ofthe-affordable-care-act/

Kaiser Family Foundation. (2018, December). Key Facts about the Uninsured Population. Retrieved from https://www.kff.org/uninsured/fact-sheet/keyfacts-about-the-uninsured-population/

Musumeci, M. (2012, August). A Guide to the Supreme Court's Decision on the ACA's Medicaid Expansion. Retrieved from https://www.kff.org/healthreform/issue-brief/a-guide-to-the-supreme-courts-decision/

Opoku, S., Akowuah, E., \& Apenteng, B. (n.d.). Impact of Medicaid Expansion on Malpractice Claims [Abstract]. American Public Health Association. Retrieved from https://apha.confex.com/apha/2018/meetingapp.cgi/ Paper/422317

Patient Protection and Affordable Care Act (2010 - H.R. 3590). (2013, April 25). Retrieved from https://www.govtrack.us/congress/bills/111/hr3590 
Small Area Health Insurance Estimates. (2017). Retrieved from https://www. census.gov/data-tools/demo/sahie/\#/?s_measures=ic_snc\&s_year=2016

Sunkara, V., \& Rosenbaum, S. (2016). The Constitution and the Public's Health. Public Health Reports,137(6), 844-846. https://doi. org/10.1177/0033354916670870

Redhead, S., \& Heisler, E. (2013). Public Health, Workforce, Quality, and Related Provisions in ACA: Summary and Timeline. Congressional Research Service. Retrieved from https://fas.org/sgp/crs/misc/R41278.pdf.

Rothstein, M. A. (2010). Health Care Reform and Medical Malpractice Claims. Journal of Law, Medicine \& Ethics. https://doi.org/10.1111/j.1748720X.2010.00540.x.

The Affordable Care Act and Property-Casualty Insurance. (2014). Insurance Research Council. Retrieved from https://www.insurance-research.org/sites/ default/files/The-Affordable-Care-Act.pdf

Zigrang, T. (2017, April). Tort Reform: The Impact of the ACA on Medical Malpractice. Retrieved from http://www.healthcapital.com/hcc/ newsletter/04_17/HTML/TORT/10.4_formatted_tort-reform-draft_4.25.php 


\section{APPENDICES:}

APPENDIX A: Regression of Malpractice Incidents on Individuals with Health Insurance and Health Consumption Expenditures from 2003 to 2017

\begin{tabular}{lr}
\hline \multicolumn{2}{c}{ Regression Statistics } \\
\hline Multiple R & 0.93981 \\
R Square & 0.88323 \\
Adjusted R Square & 0.86377 \\
Standard Error & $2,362.16292$ \\
Observations & 15 \\
\hline
\end{tabular}

\begin{tabular}{|c|c|c|c|c|c|}
\hline & $d f$ & $S S$ & $M S$ & $\boldsymbol{F}$ & Significance $F$ \\
\hline Regression & & $2506,481,621.49047$ & $253,240,810.74523$ & 45.38517 & 0.00000 \\
\hline Residual & & $12 \quad 66,957,763.84287$ & $5,579,813.65357$ & & \\
\hline Total & & $14573,439,385.33333$ & & & \\
\hline
\end{tabular}

Total $14573,439,385.33333$

\begin{tabular}{|c|c|c|c|c|c|c|c|c|}
\hline Malpractice Incidents & Coefficients & Standard Error & $t$ Stat & P-value & Lower $95 \%$ & Upper $95 \%$ & Lower $95.0 \%$ & Upper $95.0 \%$ \\
\hline Intercept & $100,026.92333$ & $23,635.84432$ & 4.23200 & 0.00116 & $48,528.84249$ & $151,525.00418$ & $48,528.84249$ & $151,525.00418$ \\
\hline Individuals with Health Insurance & -0.37026 & 0.12173 & -3.04172 & 0.01024 & -0.63547 & -0.10504 & -0.63547 & -0.10504 \\
\hline Health Consumption Expenditures & 21.55778 & 3.64166 & 5.91976 & 0.00007 & 13.62328 & 29.49228 & 13.62328 & 29.49228 \\
\hline
\end{tabular}

APPENDIX B: Regression of Malpractice Payments on Individuals with Health Insurance and Health Consumption Expenditures from 2003 to 2017

\begin{tabular}{lr}
\hline \multicolumn{2}{c}{ Regression Statistics } \\
\hline Multiple R & 0.97137 \\
R Square & 0.94355 \\
Adjusted R Square & 0.93414 \\
Standard Error & 209.45994 \\
Observations & 15 \\
\hline
\end{tabular}

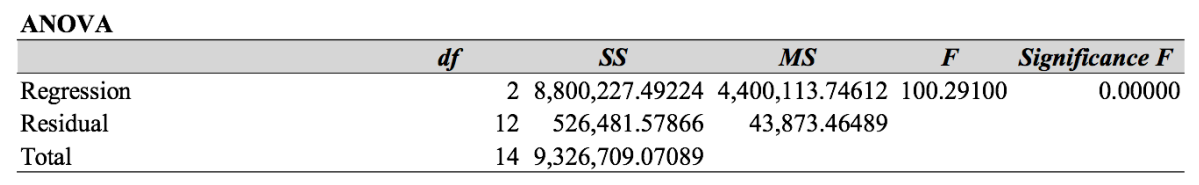

\begin{tabular}{|c|c|c|c|c|c|c|c|c|}
\hline Malpractice Payments & Coefficients & Standard Error & tStat & P-value & Lower 95\% & Upper $95 \%$ & Lower 95.0\% & Upper $95.0 \%$ \\
\hline Intercept & $-4,339.73343$ & $2,095.85986$ & -2.07062 & 0.06062 & $-8,906.21978$ & 226.75293 & $-8,906.21978$ & 226.75293 \\
\hline Individuals with Health Insurance & 0.06466 & 0.01079 & 5.99087 & 0.00006 & 0.04115 & 0.08818 & 0.04115 & 0.08818 \\
\hline Health Consumption Expenditures & -3.22371 & 0.32292 & -9.98310 & 0.00000 & -3.92729 & -2.52014 & -3.92729 & -2.52014 \\
\hline
\end{tabular}


APPENDIX C: Regression of Malpractice Payments on Individuals with Health Insurance, Health Consumption Expenditures, and Malpractice Incidents from 2003 to 2017

\begin{tabular}{lr}
\hline \multicolumn{2}{c}{ Regression Statistics } \\
\hline Multiple R & 0.97688 \\
R Square & 0.95430 \\
Adjusted R Square & 0.94183 \\
Standard Error & 196.85246 \\
Observations & 15 \\
\hline
\end{tabular}

\begin{tabular}{|c|c|c|c|c|c|c|c|c|}
\hline 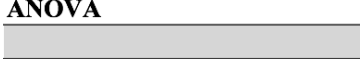 & $d f$ & SS & $M S$ & & Significance $F$ & & & \\
\hline Regression & & $8,900,449.26168$ & $966,816.42056$ & 76.56124 & $\quad 0.00000$ & & & \\
\hline Residual & & $426,259.80921$ & $38,750.89175$ & & & & & \\
\hline Total & & $9,326,709.07089$ & & & & & & \\
\hline Malpractice Payments & Coefficients & Standard Error & $t$ Stat & $P$-value & Lower 95\% & Upper $95 \%$ & Lower $95.0 \%$ & Upper $95.0 \%$ \\
\hline Intercept & $-8,209.61320$ & $3,109.70010$ & -2.64000 & 0.02299 & $-15,054.01698$ & $-1,365.20943$ & $-15,054.01698$ & $-1,365.20943$ \\
\hline Individuals with Health Insurance & 0.07899 & 0.01350 & 5.85115 & 0.00011 & 0.04928 & 0.10870 & 0.04928 & 0.10870 \\
\hline Health Consumption Expenditures & -4.05775 & 0.60088 & -6.75297 & 0.00003 & -5.38028 & -2.73521 & -5.38028 & -2.73521 \\
\hline Malpractice Incidents & 0.03869 & 0.02406 & 1.60820 & 0.13609 & -0.01426 & 0.09164 & -0.01426 & 0.09164 \\
\hline
\end{tabular}

\section{APPENDIX D: Regression of P\&C Insurance Net Income on Malpractice} Incidents from 2004 to 2017

\begin{tabular}{lr}
\hline \multicolumn{2}{c}{ Regression Statistics } \\
\hline Multiple R & 0.05445 \\
R Square & 0.00296 \\
Adjusted R Square & -0.08012 \\
Standard Error & 18.94965 \\
Observations & 14 \\
\hline
\end{tabular}

\begin{tabular}{|c|c|c|c|c|c|}
\hline ANOVA & & & & & \\
\hline & $d f$ & SS & $M S$ & $\boldsymbol{F}$ & Significance $F$ \\
\hline Regression & 1 & 12.81406 & 12.81406 & 0.03568 & 0.85332 \\
\hline Residual & 12 & $4,309.06951$ & 359.08913 & & \\
\hline Total & 13 & $4,321.88357$ & & & \\
\hline
\end{tabular}

\begin{tabular}{lrrrrrrrr}
\hline P\&C Insurance Net Income & Coefficients & Standard Error & \multicolumn{1}{c}{ t Stat } & \multicolumn{1}{c}{ P-value } & Lower 95\% & Upper 95\% & Lower 95.0\% & Upper 95.0\% \\
\hline Intercept & 32.27325 & 50.04567 & 0.64488 & 0.53114 & -76.76689 & 141.31339 & -76.76689 & 141.31339 \\
Malpractice Incidents & 0.00017 & 0.00087 & 0.18890 & 0.85332 & -0.00174 & 0.00207 & -0.00174 & 0.00207 \\
\hline
\end{tabular}




\section{APPENDIX E: Regression of P\&C Insurance Net Income on Malpractice} Payments from 2004 to 2017

\begin{tabular}{lr}
\hline \multicolumn{2}{c}{ Regression Statistics } \\
\hline Multiple R & 0.00508 \\
R Square & 0.00003 \\
Adjusted R Square & -0.08331 \\
Standard Error & 18.97756 \\
Observations & 14 \\
\hline
\end{tabular}

\begin{tabular}{|c|c|c|c|c|c|}
\hline ANOVA & & & & & \\
\hline & $d f$ & SS & MS & $F$ & Significance $F$ \\
\hline Regression & 1 & 0.11159 & 0.11159 & 0.00031 & 0.98625 \\
\hline Residual & 12 & $4,321.77198$ & 360.14766 & & \\
\hline Total & 13 & $4,321.88357$ & & & \\
\hline
\end{tabular}

\begin{tabular}{lrrrrrrrr}
\hline P\&C Insurance Net Income & Coefficients & Standard Error & $\boldsymbol{t}$ Stat & P-value & Lower 95\% & Upper 95\% & Lower 95.0\% & Upper 95.0\% \\
\hline Intercept & 41.06912 & 34.99211 & 1.17367 & 0.26330 & -35.17213 & 117.31038 & -35.17213 & 117.31038 \\
Malpractice Payments & 0.00013 & 0.00765 & 0.01760 & 0.98625 & -0.01654 & 0.01681 & -0.01654 & 0.01681 \\
\hline
\end{tabular}

